\title{
Plano diretor de São Luís-Ma: propósito e principais fatores determinantes
}

São Luís-Ma master plan: purpose and main determining factors

\author{
Willian Barbosa Filho \\ Universidade Estadual do Maranhão - São Luís - Maranhão - Brasil \\ ORCID https://orcid.org/0000-0001-5016-0713
}

\begin{abstract}
Resumo: Este artigo visa analisar a gestão do processo de revisão do Plano Diretor de São Luís - MA, identificando os fatores responsáveis pela supressão e (re) configuração, bem como a efetividade dos instrumentos institucionais de gestão participativa. A partir disso, foi feita a seguinte indagação: a revisão do Plano Diretor de São Luís atende a quais interesses? Os resultados extraídos dos registros escritos das reuniões do Conselho da Cidade constataram que os principais determinantes da dinâmica de conformação espacial de São Luís- MA são os movimentos de expansão urbana em conjunto com a especulação imobiliária, agronegócio e atividades industriais conduzidos por políticas desenvolvimentistas.
\end{abstract}

Palavras-chave: Gestão Participativa. Conformação espacial. Políticas Públicas. Políticas Desenvolvimentistas.

\begin{abstract}
This article aims to analyze the management of the revision process of the 'Master Plan of São Luís - MA, identifying the factors responsible for the suppression and (re) configuration, as well as the effectiveness of institutional instruments of participative management. Based on that, the following question was asked: which revisions to the São Luís Master Plan did I attend to? The results extracted from the written records of the meetings of the City Council found that the main determinants of the dynamics of spatial conformation in São Luís-MA are the movements of urban expansion together with real estate speculation, agribusiness and industrial activities driven by developmental policies.
\end{abstract}

Keywords: Participative Management. Spatial conformation. Public policy. Developmental policies. 


\section{Introdução}

O Plano Diretor de São Luís, criado por meio da Lei no 4.669, de 11 de outubro de 2006, passou por uma revisão no que diz respeito ao uso e ocupação do solo, infraestrutura e definição espacial das atividades socioprodutivas nos limites urbanos da cidade. Trata-se de um importante instrumento na evolução da paisagem urbana e melhoria da qualidade de vida da população, além de ser, ou não, um importante aliado na conservação e gestão das Áreas de Proteção Ambiental.

Para Villaça (2004, pp. 238) o Plano Diretor se constitui como:

Um plano que, a partir de um diagnóstico científico da realidade física, social, econômica, política e administrativa da cidade, do município e de sua região, apresentaria um conjunto de propostas para o futuro desenvolvimento socioeconômico e futura organização espacial dos usos do solo urbano, das redes de infraestrutura e de elementos fundamentais da estrutura urbana, para a cidade e para o município, propostas estas definidas para curto, médio e longo prazos, e aprovadas por lei municipal.

Existe uma visão consensual das competências e abrangência do Plano Diretor pautado pela Constituição Federal de 1988. E, apesar da influência do urbanismo moderno (dos embates dos atores sociais envolvidos e seus instrumentos), contém instrumentos como as ZIS (Zonas de Interesse Social), o que torna prioridade a formulação de política pública em detrimento da visão linear de planejamento urbano. Segundo Avritzer (2010), ocorreu uma quebra de paradigma na percepção sobre as cidades, onde a noção de gestão urbana passou a ganhar força, ou seja, a ideia de que as políticas públicas deveriam ser ordenadas com base na gestão dos recursos, seja natural ou não, com objetivo de proporcionar equidade urbana.

Porém, a efetividade desses planos no contexto urbano é outra questão que remete à ineficácia na autoaplicação desse instrumento, bem como de outros mecanismos, como planos de manejo. Nesse sentido, o dilema consiste exatamente no papel inócuo que esses instrumentos legais de planejamento desempenham, seja por limitações relacionadas às suas competências, como no caso dos municípios que devem observar dentro dos seus limites o que cabe às instâncias Estaduais e Federais, seja pela atuação dos grupos relacionados ao capital imobiliário que não têm interesse na aplicação de normas que restrinjam sua expansão.

Segundo Villaça (2004, pp. 240),

A elite econômica brasileira - no caso representada pelos interesses imobiliários - não quer saber de plano diretor, pois ele representa uma oportunidade para debater os ditos "problemas urbanos" que ela prefere ignorar. A experiência recente em diversas capitais (Rio de Janeiro, Belém, São Paulo), revela claramente que as forças e interesses do setor imobiliário não querem saber de plano diretor. Nesse sentido, essas forças e interesses veem propugnando por um plano diretor apenas de princípios gerais. 
Em São Luís, observa-se um contexto semelhante, pois o Plano Diretor em 2006, não efetivou a maioria das suas diretrizes, situação que tem raízes na forma como o município se urbanizou, uma reconfiguração espacial que a princípio foi direcionada para o Norte da cidade no sentido de interligar a parte central às praias, com a construção da Ponte José Sarney e a consequente valorização imobiliária da área que hoje correspondente ao São Francisco, Renascença, Calhau, São Marcos, Laguna da Jansen e Olho D'água (RIBEIRO JúNIOR, 1999).

Posteriormente, com o aumento do contingente populacional outra reconfiguração espacial foi realizada na direção Sudoeste da capital maranhense, considerada zona periférica e que hoje engloba os bairros do Anjo da Guarda, Vila Nova, Fumacê, Vila Embratel, Sá Viana, Vila Maranhão, Rio dos Cachorros, Vila Sarney e Maracanã. $O$ intuito com essa frente de expansão era estabelecer a ligação entre o Porto do Itaqui e a Zona Central de São Luís.

Essa expansão dicotômica foi determinante para a priorização dos equipamentos de infraestrutura na cidade e formulação das políticas públicas setoriais e regras de ordenamento, com maiores investimentos nas chamadas zonas de atração, devido ao valor do metro quadrado dentro de uma lógica do capital privado. De 1980 a 2000, segundo Burnett (2007) outro modelo de urbanização modernista, intensificou a migração interna rural e ocupação de áreas públicas e privadas e consolidação de polos de alta renda e dos conjuntos habitacionais subsidiados pelo governo federal. Esses foram decisivos na dinâmica de deslocamentos que hoje gera impactos ambientais nas APAs existentes na cidade,

\footnotetext{
Repentinamente, a cidade se viu tomada por conjuntos habitacionais voltados para a classe média e condomínios fechados para a classe alta. No entanto, aos pobres só restava a ocupação desordenada de áreas periféricas, sendo muitas dessas áreas, de proteção ambiental ou ambientalmente frágeis (RIBEIRO JÚNIOR, 1999, pp. 67).
}

Esse quadro é reflexo do redimensionamento político e territorial baseado em um projeto colonização dirigida, através do Plano de Integração Nacional, que incrementou a migração, principalmente a partir de 1980, com a instalação do Programa Grande Carajás. A reestruturação espacial da APA do Maracanã se deu por meio desse fenômeno de mobilidade da força de trabalho, atraída pelos investimentos econômicos, que contribui para o crescimento demográfico da área (FERREIRA, 2017).

Tendo em vista esses aspectos, a construção do Plano Diretor de 2006, apesar de ter seguido os ritos previstos no Estatuto da Cidade (Lei 10.257 de 10 de julho de 2001) com o cumprimento de audiências públicas, reuniões setoriais e oficinas temáticas de capacitação, além da realização de uma conferência municipal (com a participação de delegados de diversos setores públicos e representantes da sociedade 
civil organizada), observa-se várias lacunas e divergências entre as dimensões técnicas e comunitárias.

Conforme avaliação de Brito (2009, p. 52) sobre a efetividade das audiências públicas,

\begin{abstract}
Nas audiências e oficinas realizadas nos bairros, as reclamações e/ou sugestões dos moradores se atinham a maioria das vezes a questões relacionadas à infraestrutura precária existente nos bairros em que residiam. Muitos dos presentes compareciam as reuniões organizadas pela prefeitura sem a clareza específica do que realmente seria debatido. E em praticamente $100 \%$ das reuniões vigorou a linguagem técnica pelos que conduziam os debates, fato que gerava o esvaziamento das reuniões ou a incompreensão dos debates pelos moradores presentes.
\end{abstract}

Esses embates suscitaram vários entraves para a participação popular. Predominou o discurso tecnocrata que não permitiu o debate com a sociedade civil e sim uma mera exposição técnica e informativa do que já foi articulado em nível institucional para posterior implantação.

Outro problema observado na fase inicial de implantação e monitoramento da Lei de Zoneamento foi quanto à existência de áreas já edificadas lançadas como áreas de proteção ambiental, e o inverso, áreas de proteção ambiental protegidas por legislação vigente do SNUC, consideradas como passíveis de edificação, em que devido à falta de registros técnicos, lacunas dos planos anteriores e imprecisão na demarcação das áreas, favoreceu a ocupação de forma irregular, tanto pelo capital privado quanto por pessoas oriundas do interior de estado, das áreas circunvizinhas a APA no Maracanã com aumento da pressão antrópica em áreas na UC (PLANO, 2006).

Outras urbanidades ${ }^{1}$ também foram surgindo no perímetro urbano de São Luís, sendo incorporadas e modificadas pelo Plano Diretor de 2006. A expansão em direção à área Leste da cidade, que corresponde a São José de Ribamar (mas também os conjuntos da Cohab) e outros bairros circunvizinhos, formaram ocupações irregulares, consolidadas por assentamentos informais. Essas alterações demostram e ratificam o aumento da pressão populacional no início dos anos 1990, que resultou no avanço do perímetro urbano para áreas mais afastadas da área central de São Luís, com um espraiamento populacional desprovido da assistência de infraestrutura básica e de ordenamento e controle.

Em relação às zonas residenciais e ao incremento populacional, pode ser citado o emblemático caso da Reserva Florestal do Sacavém, antes uma área de uso industrial, posteriormente, com o intuito da municipalidade em disciplinar a expansão urbana e também contribuir para a preservação dos remanescentes florestais da localidade, fez a mudança dessa zona para área residencial, pois se acreditava que o estabelecimento de

\footnotetext{
${ }^{1}$ Estruturação do espaço de duas formas: uma forma territorial (predomínio da contiguidade) e outra forma reticular (redes, predomínio de uma tessitura retiforme), ou seja, redes geográficas que fragmentam as cidades e criam separações e segregações espaciais (SANTOS, 2006).
} 
uma zona residencial entre essas duas áreas evitaria conflitos devido ao uso e funções distintas entre uma zona industrial e a Reserva Florestal. Mas, na prática, o que se observou na última década foi uma gradativa degradação e invasão da Reserva do Sacavém, bem como de outras áreas protegidas devido ao avanço do setor imobiliário para atender à demanda habitacional (PLANO, 2006), o que revela um descompasso entre as políticas voltadas para o ordenamento da cidade e a questão socioambiental.

Esse aspecto relacionado ao uso e ocupação do solo em São Luís configura-se como um dos determinantes da degradação ambiental, pois com o avanço da cidade decorrente da migração interna, outras atividades econômicas também começaram a ser exploradas de forma intensiva, a exemplo da extração mineral, que possui uma relação intrínseca com a construção civil. Especialmente a exploração de jazidas de areia e pedras (laterita) que constituem matéria prima na edificação de casas e prédios. 0 agravamento desse contexto se deveu, principalmente, à falta de licenciamento por parte dos órgãos competentes nas esferas estaduais e municipais: SEMA e SEMMAM, esta última vinculada à extração mineral, especificamente em áreas protegidas.

\footnotetext{
Em geral, a clandestinidade se dá pela não possibilidade de licenciamento da atividade mineradora pelo órgão competente, uma vez que a maioria das áreas exploradas está encravada em áreas protegidas por lei (Parque Estadual do Bacanga, APA do Maracanã e em regiões muitas próximas de manguezais e corpos d'água. Essa ilegalidade acaba acelerando a degradação das áreas exploradas e não permitindo o desenvolvimento de políticas (previstas em lei) voltadas para reabilitação e reutilização das áreas degradadas pela atividade mineradora. A extração de pedra e areia já é a maior causa dos processos erosivos observados na APA do Maracanã e em diversos pontos do eixo Itaqui Bacanga. Além disso, provoca também perda da qualidade das águas e assoreamento da maioria dos pequenos cursos d'agua em função da grande carga de sedimentos neles depositados. (PLANO, 2006, p. 18).
}

A intensidade dessas ações antrópicas nas bacias hídricas em São Luís, principalmente na bacia do Maracanã, ocasionou, por um lado, diversos impactos sociais, devido à compactação do solo nas margens dos cursos d'água para construção de residências, com a consequente retirada da mata ciliar e aumento do assoreamento dos rios e sedimentação, especificamente nas APAs e por outro, a utilização indiscriminada da cobertura vegetal ciliar na construção civil. Exemplo disso está na supressão do Rio Santa Bárbara e do Rio Itapiracó. 


\section{Mapa 01 - Uso e ocupação da Ilha do Maranhão}

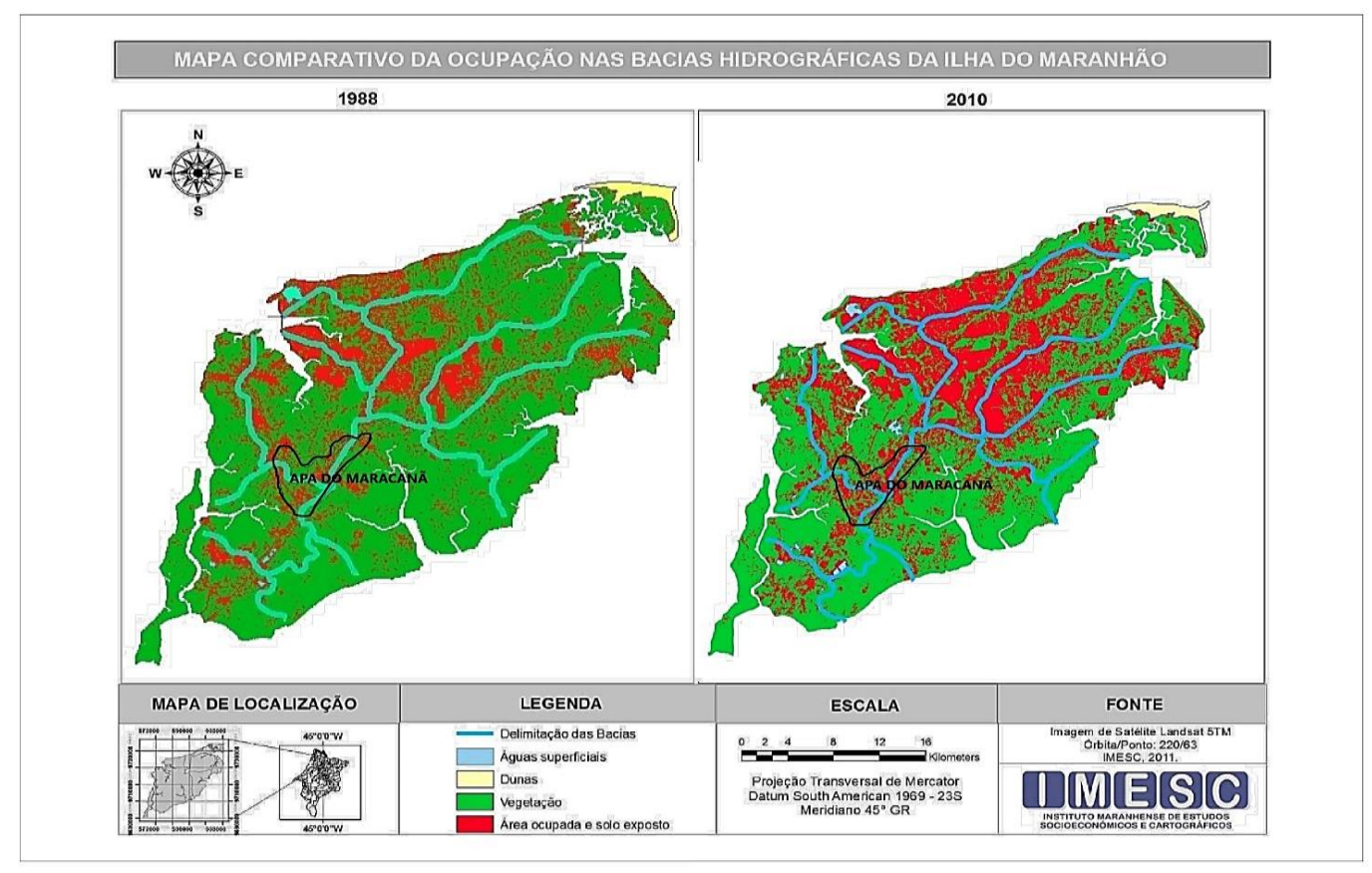

Fonte: Maranhão (2018)

Observa-se também, com base no mapa 1, que o adensamento da cidade ocorreu com maior intensidade no sentido Centro-Oeste da Grande São Luís, principalmente, devido ao avanço do setor imobiliário e instalação de vários empreendimentos, como exemplo a empresa Frango Americano no Km-2 da MA-201, Paço Lumiar, onde ocorre uma forte pressão sobre a comunidade. Fato este que é endossado pela Câmara de Vereadores do Município, que permitiu que a empresa urbanizasse extensas áreas na região do Pau Deitado. A falta de consonância entre as diretrizes e artigos do Plano Diretor e os programas de gestão das Áreas de Proteção Ambiental configura-se como um determinante para sua supressão, bem como adaptação e adição das urbanidades decorrentes das reconfigurações do tecido urbano da capital maranhense que não atendem os preceitos necessários para tornar a cidade sustentável.

Essa concepção de expansão urbana que se perpetua através das políticas de Estado que historicamente sempre privilegiou um modelo de organização espacial pautado na reprodução do capital e das suas classes dominantes, configura-se como centros de desigualdade socioambientais (VILLAÇA, 2004). Concepção institucionalizada pelas formas de planejamento e planos que na sua essência excluía as camadas populares do debate sobre a conformação das cidades.

Apesar da narrativa democrática formalizada na Lei no 10.257/01, que institui o Estatuto das Cidades e que regulamenta os artigos 182 da Constituição Federal de 
1988 que estabelece as diretrizes gerais para o ordenamento urbano e a participação social na gestão urbana,

\begin{abstract}
As consequências que assumem as lutas políticas em torno da questão urbana estão relacionadas com o caráter dado ao projeto reformista que, no seu objetivo de afirmar e ampliar os espaços públicos e, consequentemente, os direitos das camadas populares perante a sociedade, tem sido incapaz de se sobrepor aos interesses das classes dominantes, desde sempre encastelados no interior do mesmo Estado a ser reformado (VILLAÇA, 2004, p. 69).
\end{abstract}

Sendo assim, determinados interesses conflitantes presentes na dimensão do planejamento urbano se contrapõem aos princípios do desenvolvimento sustentável que norteiam a gestão ambiental. Tal fenômeno pode ser observado na atual proposta do Plano Diretor de São Luís, que propõe alterações nos artigos 26 a 40, que se referem ao macrozoneamento ambiental da capital.

\title{
Materiais e métodos
}

A compreensão de determinado tema exige a escolha de método de pesquisa (LAKATOS, MARCONI, 2010). Para efeito deste trabalho aborda-se de forma particularizada a reestruturação da rede urbana maranhense. Desse modo, foram utilizadas as seguintes técnicas: pesquisa indireta baseada em levantamento bibliográfico (livros, periódicos e similares), documental (dispositivos legais, projetos e planos de governo e relatórios técnicos públicos), cartográfico (mapa), o que possibilitou o maior entendimento de fatores que concorrem para a reconfiguração da rede urbana de São Luís - MA e a identificação de políticas públicas. A pesquisa direta foi através de visita in loco, realizada de 11/10/2019 a 19/11/2019, nas audiências públicas ocorridas na Câmara Municipal do município de São Luís, que discutiram as propostas de revisão do Plano Diretor da capital maranhense.

Nesse sentido, adotou-se nesta pesquisa uma revisão bibliográfica baseada nos principais autores: Villaça (2004), Burnett (2007), Ferreira (2017) e Ribeiro Júnior (1999) com o intuito, por meio dos seus pontos vistas acerca da noção de conformação espacial e de seus determinantes, embasar uma revisão sistemática do processo de concepção dos Planos Diretores, especificamente o de São Luís - MA, e suas formas de gestão participativa, além da sua relação com a supressão ou ampliação das áreas verdes na capital maranhense. Assim, os dados foram obtidos nas plataformas governamentais e por intermédio da análise crítica das Atas das reuniões extraordinárias do Conselho da Cidade de São Luís que antecederam as audiências públicas para discussão da revisão do Plano Diretor de São Luís. As Atas analisadas, ao todo 05, correspondem ao período de 2017 a 2018.

Posteriormente, como se trata de uma pesquisa qualitativa com ênfase na revisão bibliográfica sobre o assunto proposto, foi realizado um cruzamento das 
informações obtidas em livros, artigos e sites. Os pressupostos teóricos deste trabalho são: Gestão Participativa. Conformação espacial. Politicas desenvolvimentistas. Este trabalho foi realizado em um ano de pesquisa.

\section{Resultados e discussão}

O ponto que tem gerado muitas críticas e vem sendo alvo de questionamento por parte dos movimentos sociais e populares é a proposta de supressão das áreas rurais em detrimento do avanço dos limites urbanos, que segundo ATA da 37a reunião extraordinária do Conselho da Cidade de São Luís, foi apresentada uma nova cartografia, distinta da cartografia de 2006, que previa o aumento dos limites urbanos em áreas nas quais a Prefeitura já havia licenciado uma série de construções.

O Conselho da Cidade de São Luís é um órgão colegiado de caráter deliberativo, consultivo e permanente, composto por representantes de Movimentos Sociais e Populares, Instituições de Ensino Superior, Entidades de Classe dos Trabalhadores, Sindicatos dos Empresários, Poder Público Legislativo Municipal e Estadual, Organizações Não Governamentais e Poder Púbico Executivo Municipal e Estadual. Essa reunião técnica antecedeu o início das audiências públicas, que ocorreu no dia 07 novembro de 2018, no auditório da Escola de Governo do Estado do Maranhão, em obediência ao termo de ajustamento de conduta entre a Prefeitura e o Ministério Púbico Estadual, para discussão sobre o mapa referente aos limites das áreas urbanas e rurais do município (2019).

Foi questionado se essa área abrangia o lago de rejeitos da ALUMAR, o que foi confirmado pelo representante do Instituto da Cidade, Pesquisa e Planejamento Urbano e Rural, que alegou que o trecho que será alterado é uma área própria da ALUMAR, que o processo de licenciamento para ampliação de construções na área está de acordo com a legislação, devidamente comprovado pelos pareceres técnicos municipais dados pela Secretaria Municipal de Meio Ambiente. Quando indagados sobre o período de concessão da licença ambiental e se a proposta não teria que passar antes pelo Conselho da Cidade, os representantes da prefeitura relataram que o processo foi formalizado em 2015 e 2016 e que não havia a necessidade de passar pelo Conselho da Cidade.

Vale ressaltar que essa lagoa de rejeitos da ALUMAR é do tamanho da Laguna da Jansen e semelhante ao depósito de rejeitos que rompeu em Mariana (MG) e está localizada próxima à BR-135, área industrial de São Luís, e próxima do recorte de estudo deste trabalho, APA do Maracanã.

Trata-se de um depósito de resíduos de bauxita oriundos do processo de beneficiamento do alumínio. No caso de vazamento, pode acarretar vários problemas ao meio ambiente, devido à quantidade de metais presentes nos rejeitos. Após o rompimento da barragem de Brumadinho (MG) em 2019, foi realizada uma vistoria na barragem da ALUMAR por representantes do poder público, porém não se cogitou por parte das autoridades a substituição desse modelo pela de barragem a seco, mais segura 
para a população, porém com um custo mais alto para as empresas, pois o processo consome mais tempo e energia.

Outro questionamento refere-se a concessão de licença para áreas que não estavam enquadradas no zoneamento. De acordo com o representante da prefeitura, a cessão das licenças tem o intuito de corrigir omissões constatadas no Plano Diretor de 2006, porém a correção dessa falha observada pelo órgão municipal atende aos interesses de expansão da ALUMAR na região.

Em relação ao quantitativo de áreas indicadas como urbanas e rurais na revisão do Plano Diretor, foram incluídos espaços antes não computados como urbano e rural, entre eles as áreas de mangue, que no Plano Diretor de 2006 eram classificadas como Área de Preservação Permanente. Este novo desenho apresentado pelos representantes da prefeitura, baseada em dados cartográficos e imagens de satélite para realização dos estudos, indicaram um crescimento além dos limites estabelecidos no Plano de 2006.

Outro ponto levantado diz respeito à demanda de 20 comunidades da Zona Rural 2, composta pelos povoados de Taim, Rio dos Cachorros, Cajueiro, Parnauaçu, Porto Grande, Vila Maranhão, Ananandiba, Colier, São Benedito, Vila Madureira e Camboa dos Frades, que se localizam na porção oeste da cidade, para criação da Reserva Extrativista de Tauá Mirim em São Luís.

De acordo com a nova cartografia esta região será impactada pela expansão dos limites da cidade, sendo classificadas como áreas de Consolidação 2 , que segundo a Lei n. 4.6169/06 (2006, p. 20) são "áreas com boa infraestrutura e certo grau de urbanização, além de grande potencial para o adensamento e para a verticalização" favorecendo assim, instalação de empreendimentos privados, como o Porto chinês na parte Sul da Baía de São Marcos, especificamente no Cajueiro. Para tanto, aciona-se a velha narrativa desenvolvimentista fundamentada na perspectiva de geração de emprego e renda para a população.

Apesar do processo administrativo de iniciativa do Ministério Público Federal e Estadual, que possibilita a criação da Reserva Extrativista de Tauá-Mirim em São Luís ter sido concluído pelo IBAMA e pelo ICMBio, a prefeitura e o governo do estado desconsideram essa decisão judicial. Pretendem com a proposta cartográfica do novo Plano Diretor dar continuidade à expansão industrial em São Luís, com o deslocamento de várias comunidades tradicionais que residem na área. Outra preocupação apresentada pelo representante da Universidade Federal do Maranhão foi sobre áreas que ficam no entorno da BR-135, compostas por várias zonas de recarga de aquífero, pois de acordo com a proposta da prefeitura, a área será transformada em zona urbana com objetivo de ampliar o Distrito Industrial, medida que coloca em risco os recursos hídricos da cidade.

O Sindicato dos Trabalhadores e Trabalhadoras Rurais de São Luís também questionou a ampliação dos limites urbanos sobre área do Taim e Rio dos Cachorros, afirmando que o novo mapa proposto se opõe ao que foi acordado anteriormente sobre a manutenção das áreas rurais. O representante da Central Sindical e Popular Conlutas, 
também, questionou à postura do poder público ao privilegiar os interesses do capital privado, provocando com isso a supressão dessa área rural.

Com o isolamento da região do Taim e Rio dos Cachorros se criaria as condições favoráveis para expansão de empreendimentos privados em São Luís, desrespeitando as decisões do Ministério Púbico Federal e Estadual sobre a zona rural, inclusive do Instituto do Patrimônio Histórico e Artístico Nacional sobre sítios arqueológicos com o visível objetivo de instalar um porto privado na região do Cajueiro.

Esse, novo redesenho do Plano Diretor passa, inclusive, por cima da decisão do IBAMA, que autorizou a criação da RESEX de Tauá Mirim. Diante das polêmicas geradas em relação à expansão dos imites urbanos sobre áreas rurais, os representantes dos movimentos sociais e populares propuseram que a Ata não fosse aprovada naquele momento e as comunidades envolvidas fossem convidadas para participar do debate.

O pedido ensejou a votação de duas propostas: uma que adiava a aprovação para discutir o tema com a participação das comunidades que residem nas áreas que serão alteradas e a segunda, que determinava a votação da Ata no mesmo dia. A favor da primeira proposta votaram, os conselheiros e representantes do IFMA, UFMA, Sindicato das Indústrias Urbanas de São Luís, Central Sindical e Popular Conlutas, Movimento de Defesa da Ilha, União Estadual por Moradia Popular, Sindicato dos Trabalhadores e Trabalhadoras Rurais de São Luís, Associação dos Professores da UFMA e Associação Comunitária Itaqui Bacanga

$\mathrm{Na}$ segunda, votaram, os conselheiro e representante da Assembleia Legislativa, Sindicato da Indústria da Construção Civil do Maranhão, Secretaria de Estado de Indústria, Comércio e Energia do Maranhão, Federação das Indústrias do Estado do Maranhão, Secretaria de Estado das Cidades e Desenvolvimento Urbano, 02 votos da Câmara de Vereadores (única entidade do conselho que possui 02 titulares), Secretaria Municipal de Planejamento e Desenvolvimento, Conselho de Arquitetura e Urbanismo do Maranhão, Secretaria Municipal de Meio Ambiente, Instituto Municipal de Paisagem Urbana, Secretaria Municipal de Paisagem Urbana, Secretaria Municipal de Projetos Especiais, Instituto da Cidade, Pesquisa e Planejamento Urbano e Rural e Secretaria Municipal de Urbanismo e Habitação, totalizando 16 votos.

Pode se dizer que durante audiências públicas realizadas entre 15 de janeiro e 02 de fevereiro de 2019, os representantes municipais e legislativos apresentaram complexos dados cartográficos em linguagem inacessível à população. Não houve adequado embasamento técnico e conexão com a realidade das comunidades rurais para confirmar a real necessidade socioambiental de extensão dos limites da cidade e a urgência de urbanizar as áreas rurais, pois existem outras demandas ainda não discutidas, como saneamento básico e infraestrutura. Como justificativa, valem-se da falaciosa narrativa de que São Luís tem um grande potencial industrial que beneficiará a todos.

A minuta da proposta final do Plano Diretor de São Luís, Lei no 4.669/06, prevê alterações do Macrozoneamento Ambiental e encontra-se na Câmara de Vereadores. 
Caso seja aprovada, São Luís perderá 8.643 hectares de zona rural, bem como diminuirão suas áreas de recarga de aquífero, além da mudança de categoria de Áreas de Proteção, como a do Sítio Santa Eulália, de acordo com as alterações do Art. 26, fragilizando e permitindo a expansão urbana.

Essa conjuntura histórica de afrouxamento do poder municipal sobre o controle e o disciplinamento da produção espacial em São Luís indica, em relação à criação das novas zonas urbanas, uma fragilização das áreas verdes, além do aumento dos conflitos, colocando em risco as comunidades tradicionais.

\section{Conclusão}

O presente trabalho pretendeu responder às questões referentes ao objeto de estudo apresentado que se baseou na análise da gestão do processo de revisão do Plano Diretor de São Luís - MA, identificando os fatores responsáveis pela supressão e (re) configuração espacial das áreas verdes, bem como a efetividade dos instrumentos institucionais de gestão participativa.

Diante do exposto, verificou-se que o Estado possui grande influência na produção do espaço urbano, especificamente, por meio de intervenções, articulações e inclusive, das omissões. Ainda, constatou-se, com base na pesquisa, que os detentores dos meios de produção e os agentes imobiliários reproduzem o capital no município de São Luís.

Ainda, a partir dos pressupostos teóricos apresentados e dos resultados da pesquisa verificou-se que o modelo de desenvolvimento urbano de grandes cidades é baseado em um adensamento social e espacial no qual a negligência à dimensão humana originou modelos urbanísticos impróprios e consolidados por formas de planejamento desestruturadas em detrimento de um modelo urbano mais sustentável.

Sendo assim, sobre a problemática apresentada neste trabalho, observa-se que o Estado como ator social responsável pela acumulação e reprodução do capital, no caso do Plano Diretor, apesar de espremido pelos interesses do setor privado de um lado e pelas reivindicações da população do outro, tem cedido às pressões do capital imobiliário, do agronegócio e da industrial.

Portanto, constatou-se que os principais determinantes da dinâmica de revisão do Plano Diretor de São Luís, são os movimentos de expansão urbana em conjunto com a especulação imobiliária, agronegócio e atividades industriais conduzidos por políticas desenvolvimentistas. 


\section{Referências}

BRITO, Cilícia Dias dos Santos Belfort. O processo de uso e ocupação do solo urbano previsto no plano diretor de São Luís - MA. 105 fs. Dissertação (Mestrado em Geografia) - Fundação Universidade Federal de Rondônia, 2009.

BRASIL. Presidência da República. Casa Civil. Subchefia para Assuntos Jurídicos. LEI № 10.257, DE 10 DE JULHO DE 2001. Regulamenta os arts. 182 e 183 da Constituição Federal, estabelece diretrizes gerais da política urbana e dá outras providências. Disponível em:< https://www2.camara.leg.br/legin/fed/lei/2001/lei-10257-10-julho2001-327901-publicacaooriginal-1-pl.html>. Acesso em: 20 out. 2019.

BURNETT, Frederico Lago. Da cidade unitária à metrópole fragmentada: crítica a constituição da São Luís moderna. In: LIMA, Antônia Jesuíta de. (Org.). Cidades brasileiras: atores, processos e gestão pública. Belo Horizonte: Autêntica, 2007.

FERREIRA, Antônio José de Araújo. A reestruturação urbana maranhense: dinâmica e perspectivas. São Luís: EDUFMA, 2017.

MARCONI, Marina de Andrade; LAKATOS, Eva Maria. Fundamentos de metodologia científica. 7.ed. São Paulo: Atlas, 2010.

RIBEIRO JÚNIOR, José Reinaldo Barros. Formação do Espaço Urbano de São Luís. São Luís: Edições FUNC, 1999.

MARANHÃO. Instituto Maranhense de estudos socioeconômicos e cartográficos. Diálogos Metropolitanos do PDDI da Grande São Luís. 2018. Disponível em: <http://imesc.ma.gov.br/portal/Post/noticias/610/>. Acesso em: 28 maio 2018.

PLANO diretor de São Luís. 2006. Disponível em: $<$ https://www.saoluis.ma.gov.br/midias/anexos/1188_8-

lei_n.4.669_de_11.10.2006_d.o.m._n.195_-_completo.pdf>. Acesso em: 28 nov. 2017.

SÃO LUís. Prefeitura Municipal de São Luís. 2017. Lei no 4669/2006. Disponível em:<http://www.saoluis.ma.gov.br/busca.asp/>. Acesso em: 19 set. 2017.

VILLAÇA, Flávio. Dilemas do Plano Diretor. In: . (Org.) CEPAM. O município no século XXI: cenários e perspectivas. São Paulo: Cepam, 2004.

\section{Sobre o autor:}

Willian Barbosa Filho, departamento de ciências socias, mestrado de desenvolvimento socioespacial e regional, Universidade Estadual do Maranhão - São Luís - Maranhão Brasil. Email: willian.setur@hotmail.com 